\title{
Article \\ Specific Detection of PE-Included Vesicles Using Cyclic Voltammetry
}

\author{
Yeseul Park and Jin-Won Park *
}

check for updates

Citation: Park, Y.; Park, J.-W. Specific Detection of PE-Included Vesicles Using Cyclic Voltammetry. Appl. Sci. 2021, 11, 3660. https:// doi.org/10.3390/app11083660

Academic Editors:

Domenico Lombardo and Cédric Delattre

Received: 3 March 2021

Accepted: 13 April 2021

Published: 19 April 2021

Publisher's Note: MDPI stays neutral with regard to jurisdictional claims in published maps and institutional affiliations.

Copyright: (c) 2021 by the authors. Licensee MDPI, Basel, Switzerland. This article is an open access article distributed under the terms and conditions of the Creative Commons Attribution (CC BY) license (https:// creativecommons.org/licenses/by/ $4.0 /)$.
Department of Chemical and Biomolecular Engineering, College of Energy and Biotechnology, Seoul National University of Science and Technology, 232 Gongneung-ro, Nowon-gu, Seoul 01811, Korea; grso2003@naver.com * Correspondence: jwpark@seoultech.ac.kr; Tel.: +82-2-970-6605

\begin{abstract}
The binding between cinnamycin and the phosphatidylethanolamine (PE)-included vesicles was monitored using cyclic voltammetry $(\mathrm{CV})$ measurements and interpreted in terms of the composition of the vesicles and the monolayer binding site. The monolayer was composed of pure 11-mercapto-1-undecanol (MUD) to 90\% MUD/10\% 16-mercaptohexadecanoic acid (MHA) on a gold surface. Cinnamycin was immobilized on each monolayer. The vesicles, prepared at the desired ratio of the phospholipids, were injected on the cinnamycin-immobilized surface. CV experiments were performed for each step. For the pure-dipalmitoylphosphatidyl-choline (DPPC) vesicles on all of monolayers and the DPPC/dipalmitoylphosphatidyl-ethanolamine (DPPE) vesicles on the pureMUD monolayer, the electric property of the surface was little changed. However, the vesicles made with $90 \%$ DPPC /10\% DPPE on the monolayer prepared with $99 \%$ MUD/1\% MHA to 90\% MUD/10\% MHA showed a consistent decrease in the CV response. Additionally, in the 95\% DPPC/5\% DPPE vesicles and the $99.5 \%$ MUD/0.5\% MHA monolayer, variances in the responses were observed.
\end{abstract}

Keywords: cinnamycin; phosphatidylethanolamine; specific binding; vesicle composition; surface density

\section{Introduction}

Cinnamycin, a 19-amino acid tetracyclic peptide, is a globular electrically neutral peptide capable of forming an equimolecular complex with phosphatidylethanolamine (PE) specifically [1,2]. The specific formation is generated due to its unique structure: most of the hydrophobic amino acids are positioned at one side of the peptide, whereas the hydrophilic one is located on the other side. Both the headgroup and the hydrocarbon chains of PE are crucial for interaction with the peptide [3]. The hydrophilic side of the peptide binds to the headgroup, and then the binding is enhanced by hydrophobic interaction [2]. The specificity has led the cinnamycin to be used for the investigation of PE-related mechanisms such as apoptosis, cell division, migration and tumor vasculature [4-8]. Furthermore, this peptide has been considered as not only a potential probe for disrupting PE-containing membranes, such as those of cancer cells and bacteria, but also an alternative treatment for atherosclerosis $[9,10]$. The physical characteristics of its specificity, i.e., binding affinity, thermodynamic properties and structural changes, have been investigated using enzymelinked immuno-sorbent assay (ELISA), isothermal titration calorimetry, small-angle X-ray scattering, transmission electron microscopy and surface plasmon resonance [2,11-13].

Spherical phospholipid bilayers, named vesicles, are widely-used as a model of the cell surface and also for investigating molecular events in membranes because the preparation methodology for the lipid bilayers has been well established and highly sensitive analytical techniques can be applied to investigate the events [14-18]. The vesicles have also been important for biomedical research of cell recognition, antimicrobial peptide activity, drug delivery and disease diagnosis [19-22]. Cyclic voltammetry (CV) has proved a valuable tool for direct, label-free, and noninvasive detection of surface binding in real-time at pM-scale sensitivity [23]. Surface binding includes the molecular adsorption, nucleic-acid 
hybridization and antibody-antigen interaction [24-26]. In this work, we aim to determine the characteristics of the specific binding between the cinnamycin and the vesicle with an outer layer of PE inclusion using CV. These characteristics may provide a platform for the cinnamycin-based development of therapy or diagnosis.

\section{Materials and Methods}

\subsection{Vesicle Preparation}

For vesicle preparation, dipalmitoylphosphatidylcholine (DPPC) and dipalmitoylphosphatidylethanolamine (DPPE) from Avanti were dissolved at 90:10 and 95:5 molar ratios (DPPC:DPPE), or pure DPPC was used, in chloroform. These ratios were determined from $1.1 \mu \mathrm{M}$ cinnamycin behavior, which was found to be identical on the membrane at more than $10 \%$ PE [27]. The chloroform was subsequently evaporated under a dry stream of nitrogen to form lipid films at the wall of a glass tube. The inside glass tube was at low pressure for several hours to remove the last traces of the solvent and immersed overnight at room temperature in $2 \mathrm{~mL}$ of a buffer containing $10 \mathrm{mM}$ Hepes, $50 \mathrm{mM} \mathrm{KCl}$, and $1 \mathrm{mM} \mathrm{NaN}_{3}$ at $\mathrm{pH}$ 7. The hydrated solution was subjected to freezing and thawing with vigorous vortexing for ten 10 min cycles, and extruded through two stacked $100 \mathrm{~nm}$ pore size polycarbonate filters at room temperature to achieve formation of the unilamellar vesicles. The vesicle solution was transferred to an instrument for dynamic light scattering (ELS-8000, Otsuka, Tokyo, Japan) to measure the diameters of the vesicles, which were distributed normally between 130 and $170 \mathrm{~nm}$.

\section{2. $C V$ Experiments}

Each step was performed for surface treatment (Figure 1), and CV response was monitored for each step. Bare gold electrode surfaces $(65 \mathrm{~mm}$ length \& $3 \mathrm{~mm}$ diameter, eDAQ, Denistone East, NSW 2112, Australia) were cleaned immediately prior to use in a $1: 4$ solution of $30 \%$ hydrogen peroxide and $96 \%$ sulfuric acid at around $70{ }^{\circ} \mathrm{C}$ for $10 \mathrm{~min}$. The gold surfaces were dried in nitrogen and immersed overnight in an ethanol solution containing $1 \mathrm{mM}$ of $100 \%$ 11-mercapto-1-undecanol (MUD) or the desired ratio of MUD and 16-mercaptohexadecanoic acid (MHA) (Sigma-Aldrich, St. Louis, MO, USA), rinsed with ethanol and dried with $\mathrm{N}_{2}$. The electrodes were then immersed for $30 \mathrm{~min}$ in a solution containing $10 \mathrm{mg} / \mathrm{mL} \mathrm{N}$-hydroxysuccinimide (Sigma-Aldrich, St. Louis, MO, USA) and $25 \mathrm{mg} / \mathrm{mL}$ 1-ethyl-3-(3-dimethylaminopropyl)-carbodiimide (Sigma-Aldrich, St. Louis, MO, USA), rinsed with ultrapure water, incubated with $0.1 \mathrm{mg} / \mathrm{mL}$ cinnamycin for $1 \mathrm{~h}$, rinsed further with PBS buffer, and immediately used without dewetting. After the cinnamycin layer formed on the electrode was transferred to the cell of the CV instrument, the solution of the vesicles was added to the electrode in the cell followed by its adsorption about $30 \mathrm{~min}$. Then, the vesicle solution was exchanged into $10 \mathrm{mM}$ Hepes, $50 \mathrm{mM} \mathrm{KCl}$, and $1 \mathrm{mM} \mathrm{NaN}_{3}$ solution to remove excess vesicles. $\mathrm{CV}$ experiments were performed with a CHI660B electrochemical workstation (CH Instruments Inc., Austin, TX, USA) in a solution containing $1 \mathrm{mM} \mathrm{K}{ }_{3} \mathrm{Fe}(\mathrm{CN})_{6}$ as a redox species. The potential was cycled, ranging from 500 to $-200 \mathrm{mV}$ relative to an $\mathrm{Ag} / \mathrm{AgCl}$ reference electrode, at a scan rate of $0.05 \mathrm{mV} / \mathrm{s}$. 


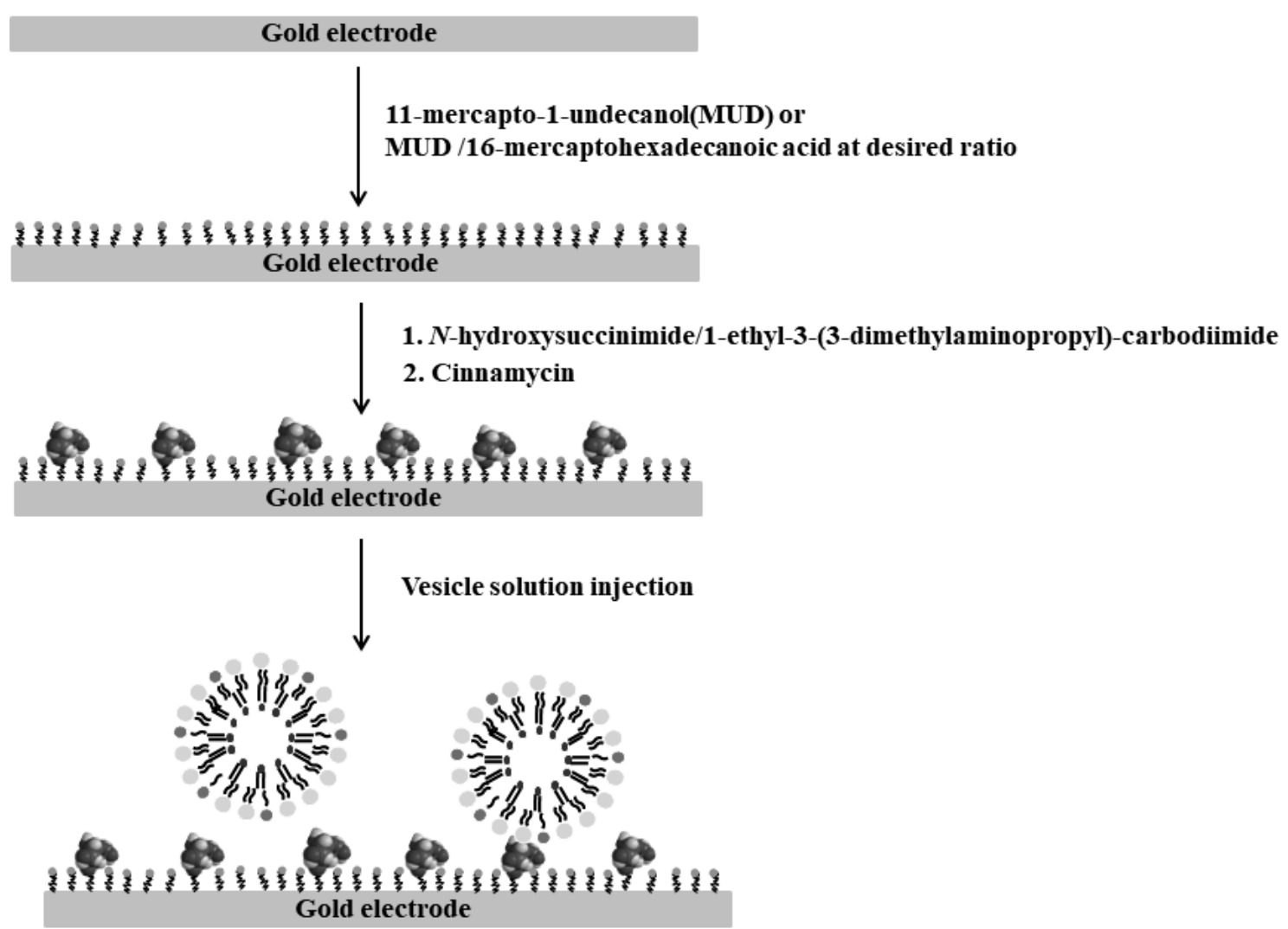

Figure 1. Surface treatment procedure on the gold electrode for CV experiments.

\section{Results and Discussion}

\subsection{Response for the Monolayer Formation on the Gold Electrode}

The electric property for each step on the gold electrode surface was detected by conducting $\mathrm{CV}$ experiments. For the monolayers made, respectively, with pure MUD and $90 \%$ MUD/10\% MHA, the current-potential responses in CV measurements are shown in Figure 2. The current was greatly decreased after the formation of the monolayer. The decrease confirmed that the layer was uniformly placed on the electrode surface. Furthermore, the intensity of the current was identical for both compositions. This identical intensity led to two possibilities. One is no effect of $10 \%$ MHA on the properties, and the other is no MHA adsorption on the electrode surface. Assuming no effect of $10 \%$ MHA, the cinnamycin was immobilized on the monolayer surface. The lack of MHA adsorption possibility is described further in the next Section 3.2. After the cinnamycin was immobilized, the response was measured again. Little change in the response was observed compared to that before the immobilization. Little change indicated that the cinnamycinimmobilized surface was heterogeneous, or the immobilization rarely occurred.

\subsection{Response after PE-Vesicle Addition}

Three types of vesicles were prepared: pure DPPC, 95\% DPPC /5\% DPPE and 90\% DPPC $/ 10 \%$ DPPE. Obviously, PE was used for the specific binding with the cinnamycin. Moreover, each of the vesicle solutions was injected into the pure-MUD monolayer up to $90 \%$ MUD $/ 10 \%$ MHA where the cinnamycin immobilization step was performed. For pure DPPC vesicles on all of monolayers, and DPPC/DPPE vesicles on the MUD monolayer, the responses varied little from the previous step (only the monolayer). Only for the case of $90 \%$ DPPC $/ 10 \%$ DPPE vesicle on the $90 \%$ MUD/10\% MHA, the response was clearly changed (Figure 3). The current was tremendously decreased. The decrease seemed to be caused by the vesicles' immobilization on the electrode surface, which seemed to prohibit the electron transfer. These results indicated that the MHA provided the site for 
the cinnamycin immobilization, as expected from the previous research [28]. Additionally, from the comparison of the responses for the vesicle and the monolayer, it was found that PE formed specific binding with cinnamycin.

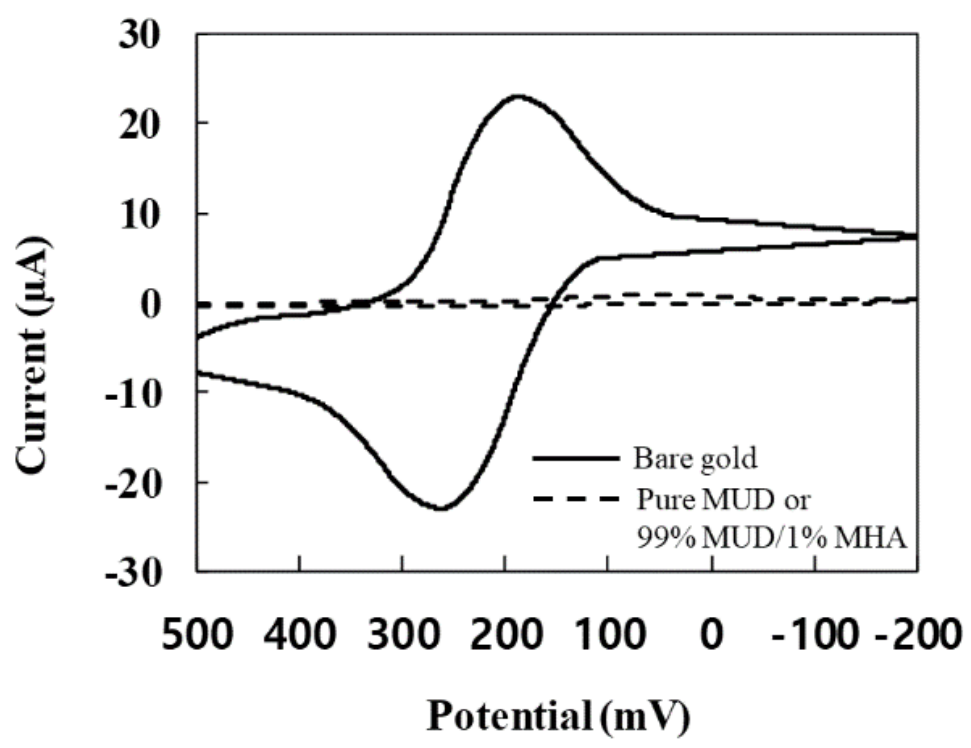

Figure 2. CV response after the monolayer formation on the gold electrode.

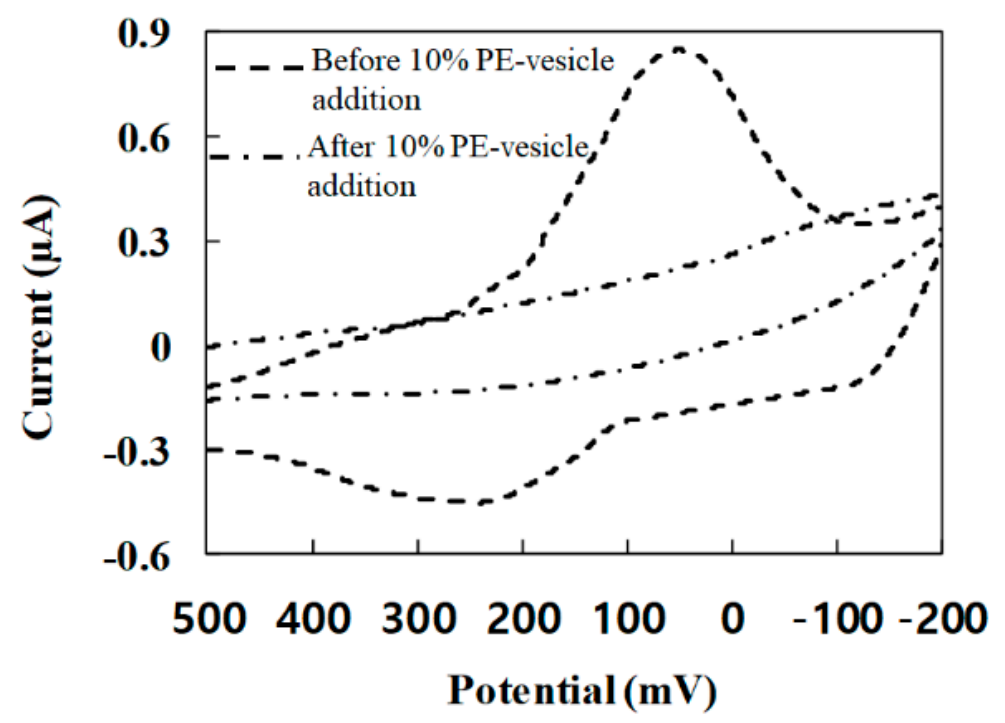

Figure 3. $\mathrm{CV}$ responses before and after the $10 \%$ PE-vesicle addition on the monolayer prepared with $90 \%$ MUD/10\% MHA.

\subsection{Response Difference for Vesicle Composition}

The values of charge $Q_{i}$ were calculated according to the equation $Q_{i}=\int I \mathrm{~d} t=\int I$ $\mathrm{d}(E / v)=(1 / v) \int I \mathrm{~d} E=\int I \mathrm{~d} t$, in which $Q_{i}$ is integrated from the potential scan rate of $-200 \mathrm{mV}$ to $500 \mathrm{mV}, I$ is the current $(\mu \mathrm{A}), E$ is the potential $(\mathrm{V})$, and $v$ is the sweep rate $0.05 \mathrm{~V} / \mathrm{s}$ [29]. The charge $Q_{i}(\mu \mathrm{C})$ at each step is listed in Table 1.

Ninety-five percent of charge transfer was blocked after the monolayer of the pure MUD or $90 \%$ MUD $/ 10 \%$ MHA was formed (the charge transfer at the gold electrode was assumed as $100 \%$ ). The compositions of the monolayer had little effect on the amount of the charge transferred to the electrode. The addition of the cinnamycin on the monolayer led to no reduction of permeability, either. For the injection of the vesicles, permeability was little changed except in the case where $90 \%$ DPPC / $10 \%$ DPPE vesicles were injected 
to the monolayer of $90 \% \mathrm{MUD} / 10 \% \mathrm{MHA}$. This result indicates that the vesicles were bound to the monolayer at a specific composition. The response for 95\% DPPC/5\% DPPE vesicles was only sometimes different from that for pure-DPPC vesicles. This inconsistency indicates that the vesicle immobilization was less uniform on the surface.

Table 1. Charge permeability with respect to each case treated on the gold electrode.

\begin{tabular}{|c|c|c|c|c|c|}
\hline \multirow{2}{*}{\multicolumn{2}{|c|}{ Step }} & \multicolumn{2}{|c|}{ Charge $(\mu \mathrm{C})$} & \multicolumn{2}{|c|}{ Charge Permeability (\%) } \\
\hline & & MUD & $\begin{array}{c}\text { 90\% MUD/10\% } \\
\text { MHA }\end{array}$ & MUD & $\begin{array}{c}90 \% \text { MUD } / 10 \% \\
\text { MHA }\end{array}$ \\
\hline \multicolumn{2}{|c|}{ Monolayer } & 1.0 & 1.0 & 5 & 5 \\
\hline \multicolumn{2}{|c|}{ Cinnamycin/Monolayer } & 1.0 & 1.0 & 5 & 5 \\
\hline \multirow{2}{*}{$\begin{array}{l}\text { Vesicles/Cinnamycin/ } \\
\text { Monolayer }\end{array}$} & DPPC & 1.0 & 1.0 & 5 & 5 \\
\hline & $\begin{array}{l}90 \% \text { DPPC } / \\
10 \% \text { DPPE }\end{array}$ & 1.0 & 0.6 & 5 & 3 \\
\hline
\end{tabular}

The consistency differences between 5\% and 10\% DPPE vesicles seemed to be caused by a steric hindrance effect. Since DPPC and DPPE are saturated phospholipids, no phaseseparation occurs in the surface of the vesicles. Presumably, the distribution of the lipids is uniform on the surface. Considering the geometry of the cinnamycin, no additional specific binding seems located, on average, within $8 \mathrm{~nm}^{2}$ around one binding site [28]. This surface density of the binding is corresponding to the composition between $5 \%$ and $10 \%$ DPPE, because the mean molecular area of DPPE is $0.6 \mathrm{~nm}^{2}$ [30]. Therefore, as long as DPPE is $10 \%$ or more, the cinnamycin appears to bind to PE at any orientation. This interpretation of the surface density is also consistent in terms of the composition of the cinnamycin density. The amount of the MHA in the monolayer was adjusted from 10 to $0.5 \%$, and the vesicles of $90 \%$ DPPC and 10\% DPPE were added to the cinnamycin for each composition of the monolayer. The CV response varied little from 10 to $1 \%$ MHA but was different at $0.5 \%$ (Figure 4 ). Considering the projection area of the vesicle, at least one cinnamycin seemed to be placed on the monolayer surface from 10 to $1 \% \mathrm{MHA}$. The theoretical value required for little change in the $\mathrm{CV}$ response was estimated at $0.1 \% \mathrm{MHA}$. Therefore, the change at $0.5 \%$ MHA indicates that equidistance between the DPPE molecules was always not maintained, although the phase separation did not occur in the lipid layer.

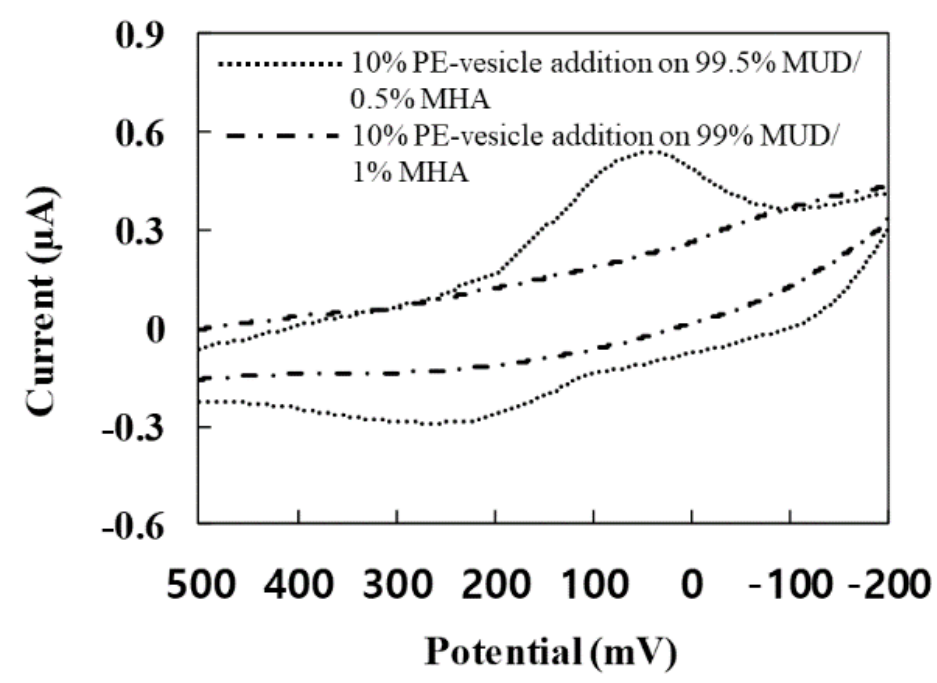

Figure 4. CV responses after the 10\% PE-vesicle addition on the monolayer prepared respectively with 99.5\% MUD/0.5\% MHA and 99\% MUD/1\% MHA. 


\section{Conclusions}

In this study, the specific binding between the cinnamycin and the PE-included vesicles was characterized with $\mathrm{CV}$ measurements. After the insulating property was confirmed for the cinnamycin immobilized on the monolayer made with different composition, the vesicles with adjusted PE ratios were added to the cinnamycin-immobilized monolayer. For the pure-DPPC vesicles on all of monolayers, and the DPPC/DPPE vesicles on the pure-MUD monolayer, the insulating property of the surface was little changed. However, the vesicles made with $90 \%$ DPPC / $10 \%$ DPPE on the monolayer prepared with $99 \%$ MUD/1\% MHA to $90 \% \mathrm{MUD} / 10 \% \mathrm{MHA}$ showed consistent reduction in the CV response. Additionally, in the $95 \%$ DPPC /5\% DPPE vesicles and the $99.5 \%$ MUD/0.5\% MHA monolayer, variance in the response was observed. Therefore, the $\mathrm{CV}$ measurement was capable of characterizing the specific binding for PE-included vesicles.

Author Contributions: Y.P. and J.-W.P. conceived, designed and drafted the research and interpreted the data, conducted the analyses, interpreted data and revised the manuscript. All authors have read and agreed to the published version of the manuscript.

Funding: This study was supported by the Research Program funded by the SeoulTech (Seoul National University of Science and Technology).

Institutional Review Board Statement: Not applicable.

Informed Consent Statement: Not applicable.

Data Availability Statement: Data is all in the paper.

Conflicts of Interest: The authors declare no conflict of interest. The funders had no role in the design of the study; in the collection, analyses, or interpretation of data; in the writing of the manuscript, or in the decision to publish the results.

\section{References}

1. Wakamatsu, K.; Choung, S.Y.; Kobayashi, T.; Inoue, K.; Higashijima, T.; Miyazawa, T. Complex formation of peptide antibiotic Ro09-0198 with lysophosphatidylethanolamine: 1H NMR analyses in dimethyl sulfoxide solution. Biochemistry 1990, 29, 113-118. [CrossRef]

2. Machaidze, G.; Ziegler, A.; Seelig, J. Specific binding of Ro 09-0198 (cinnamycin) to phosphatidylethanolamine: A thermodynamic analysis. Biochemistry 2002, 41, 1965-1971. [CrossRef] [PubMed]

3. Choung, S.Y.; Kobayashi, T.; Takemoto, K.; Ishitsuka, H.; Inoue, K. Interaction of a cyclic peptide, Ro09-0198, with phosphatidylethanolamine in liposomal membranes. Biochim. Biophys. Acta 1988, 940, 180-187. [CrossRef]

4. Emoto, K.; Kobayashi, T.; Yamaji, A.; Aizawa, H.; Yahara, I.; Inoue, K.; Umeda, M. Redistribution of phosphatidylethanolamine at the cleavage furrow of dividing cells during cytokinesis. Proc. Natl. Acad. Sci. USA 1996, 93, 12867-12872. [CrossRef] [PubMed]

5. Kato, U.; Inadome, H.; Yamamoto, M.; Emoto, K.; Kobayashi, T.; Umeda, M. Role for Phospholipid Flippase Complex of ATP8A1 and CDC50A Proteins in Cell Migration. J. Biol. Chem. 2013, 288, 4922-4934. [CrossRef] [PubMed]

6. Tafesse, F.G.; Vacaru, A.M.; Bosma, E.F.; Hermansson, M.; Jain, A.; Hilderink, A.; Somerharju, P.; Holthuis, J.C.M. Sphingomyelin synthase-related protein SMSr is a suppressor of ceramide-induced mitochondrial apoptosis. J. Cell Sci. 2014, 127, 445-454. [CrossRef] [PubMed]

7. Stafford, J.H.; Thorpe, P.E. Increased exposure of phosphatidylethanolamine on the surface of tumor vascular endothelium. Neoplasia 2011, 13, 299-308. [CrossRef] [PubMed]

8. Phoenix, D.A.; Harris, F.; Mura, M.; Dennison, S.R. The increasing role of phosphatidyl ethanolamine as a lipid receptor in the action of host defence peptides. Prog. Lipid Res. 2015, 59, 26-37. [CrossRef] [PubMed]

9. Vestergaard, M.; Berglund, N.A.; Hsu, P.-C.; Song, C.; Koldsø, H.; Schiøtt, B.; Sansom, M.S.P. Structure and Dynamics of Cinnamycin-Lipid Complexes: Mechanisms of Selectivity for Phosphatidylethanolamine Lipids. ACS Omega 2019, 4, 18889-18899. [CrossRef] [PubMed]

10. Okesli, A.; Cooper, L.E.; Fogle, E.J.; van der Donk, W.A. Nine Post-translational Modifications during the Biosynthesis of Cinnamycin. J. Am. Chem. Soc. 2011, 133, 13753-13760. [CrossRef]

11. Makino, A.; Baba, T.; Fujimoto, K.; Iwamoto, K.; Yano, Y.; Terada, N.; Ohno, S.; Sato, S.B.; Ohta, A.; Umeda, M.; et al. Cinnamycin (Ro 09-0198) promotes cell binding and toxicity by inducing transbilayer lipid movement. J. Biol. Chem. 2003, 278, 3204-3209. [CrossRef]

12. Emoto, K.; Kuge, O.; Nishijima, M.; Umeda, M. Isolation of a Chinese hamster ovary cell mutant defective in intramitochondrial transport of phosphatidylserine. Proc. Natl. Acad. Sci. USA 1999, 96, 12400-12405. [CrossRef]

13. Lee, S.-R.; Park, Y.; Park, J.-W. Kinetic and thermodynamic studies of cinnamycin specific-adsorption on PE-Included-Membranes using surface plasmon resonance. J. Biotechnol. 2020, 320, 77-79. [CrossRef] [PubMed] 
14. López-Cobo, S.; Campos-Silva, C.; Moyano, A.; Oliveira-Rodríguez, M.; Paschen, A.; Yáñez-Mó, M.; Blanco-López, M.C.; Valés-Gómez, M. Immunoassays for scarce tumour-antigens in exosomes: Detection of the human NKG2D-Ligand, MICA, in tetraspanin-containing nanovesicles from melanoma. J. Nanobiotechnol. 2018, 16, 47. [CrossRef]

15. Carnell-Morris, P.; Tannetta, D.; Siupa, A.; Hole, P.; Dragovic, R. Analysis of Extracellular Vesicles Using Fluorescence Nanoparticle Tracking Analysis. Methods Mol. Biol. 2017, 1660, 153-173.

16. Zhang, H.; Lyden, D. Asymmetric-flow field-flow fractionation technology for exomere and small extracellular vesicle separation and characterization. Nat. Protoc. 2019, 14, 1027-1053. [CrossRef]

17. Marchisio, M.; Simeone, P.; Bologna, G.; Ercolino, E.; Pierdomenico, L.; Pieragostino, D.; Ventrella, A.; Antonini, F.; Zotto, G.D.; Vergara, D.; et al. Flow Cytometry Analysis of Circulating Extracellular Vesicle Subtypes from Fresh Peripheral Blood Samples. Int. J. Mol. Sci. 2021, 22, 48. [CrossRef]

18. Yang, Y.; Zhai, C.; Zeng, Q.; Khan, A.L.; Yu, H. Multifunctional Detection of Extracellular Vesicles with Surface Plasmon Resonance Microscopy. Anal. Chem. 2020, 92, 4884-4890. [CrossRef] [PubMed]

19. Huang-Doran, I.; Zhang, C.-Y.; Vidal-Puig, A. Extracellular Vesicles: Novel Mediators of Cell Communication In Metabolic Disease. Trends Endocrinol. Metab. 2017, 28, 3-18. [CrossRef] [PubMed]

20. Pinazo, A.; Pons, R.; Marqués, A.; Farfan, M.; da Silva, A.; Perez, L. Biocompatible Catanionic Vesicles from Arginine-Based Surfactants: A New Strategy to Tune the Antimicrobial Activity and Cytotoxicity of Vesicular Systems. Pharmaceutics 2020, 12, 857. [CrossRef]

21. Dang, X.T.T.; Kavishka, J.M.; Zhang, D.X.; Pirisinu, M.; Le, M.T.N. Extracellular Vesicles as an Efficient and Versatile System for Drug Delivery. Cells 2020, 9, 2191. [CrossRef] [PubMed]

22. Cha, B.S.; Park, K.S.; Park, J.S. Signature mRNA markers in extracellular vesicles for the accurate diagnosis of colorectal cancer. J. Biol. Eng. 2020, 14, 4. [CrossRef]

23. Ganesana, M.; Lee, S.T.; Wang, Y.; Venton, B.J. Analytical Techniques in Neuroscience: Recent Advances in Imaging, Separation, and Electrochemical Methods. Anal. Chem. 2017, 89, 314-334. [CrossRef]

24. Lee, S.-R.; Park, J.-W. Trehalose-Induced Variation in Physical Properties of Fluidic Lipid Bilayer. J. Membr. Biol. 2018, 251, 705-709. [CrossRef] [PubMed]

25. Raju, V.M.; Bhavana, V.; Gayathri, G.K.; Suryan, S.; Reddy, R.; Reddy, N.; Ravikumar, C.R.; Santosh, M.S. A novel disposable electrochemical DNA biosensor for the rapid detection of Bacillus thuringiensis. Microchem. J. 2020, 159, 105434. [CrossRef]

26. Jozghorbani, M.; Fathi, M.; Kazemi, S.H.; Alinejadian, N. Determination of carcinoembryonic antigen as a tumor marker using a novel graphene-based label-free electrochemical immunosensor. Anal. Biochem. 2021, 613, 114017. [CrossRef] [PubMed]

27. Lee, G.S.; Park, J.-W. Interactions of Cinnamycin-Immobilized Gold Nanorods with Biomimetic Membranes. J. Membr. Biol. 2020, 253, 37-42. [CrossRef] [PubMed]

28. Kim, S.-E.; Park, J.-W. Analysis of interactions between cinnamycin and biomimetic membranes. Colloids Surf. B Biointerfaces 2020, 185, 110595. [CrossRef] [PubMed]

29. Christ, K.; Rüttubger, H.-H.; Höpfner, M.; Rothe, U.; Bendas, G. The detection of UV-induced membrane damages by a combination of two biosensor techniques. Photochem. Photobiol. 2005, 81, 1417-1423. [CrossRef]

30. Park, J.W.; Ahn, D.J. Temperature effect on nanometer-scale physical properties of mixed phospholipid monolayers. Colloids Surf. B Biointerfaces 2008, 62, 157-161. [CrossRef] [PubMed] 